\title{
Cirurgia conservadora da endocardite bacteriana aguda da valva tricúspide
}

\author{
Iseu Affonso da COSTA*, José Carlos MULASKI ${ }^{\star \star}$, Luiz Roberto Macedo LOPES ${ }^{\star \star}$, Cláudio Pereira da \\ CUNHA $^{\star \star *}$, Admar Moraes de SOUZA**
}

RBCCV 44205-59

COSTA, I. A.; MULASKI, J. C.; LOPES, L. R. M.; CUNHA, C. P.; SOUZA, A. M. - Cirurgia conservadora da endocardite bacteriana aguda da valva tricúspide. Rev. Bras. Cir. Cardiovasc., 3(2): 125-129, 1988

RESUMO: É relatado o caso de 1 paciente que apresentou endocardite aguda da valva tricúspide pós-aborto, cujo agente causal era o $S$. aureus. Como não houvesse resposta favorável ao tratamento antibiótico (gentamicina, vancomicina e oxacilina), optou-se pela intervenção, vinte dias após a internação. Foi praticada excisão de uma vegetação única e do tecido valvar adjacente, na comissura ântero-posterior e plicatura anular. O resultado foi favorável, com cura clínica. O exame ecocardiográfico confirmou a presença da vegetação no pré-operatório e o funcionamento conservado da valva, após a plastia. 0 tratamento cirúrgico, com retirada do tecido infectado e preservação da valva constitui uma alternativa aplicável a certos casos de endocardite aguda das valvas atrioventriculares.

DESCRITORES: endocardite bacteriana, cirurgia; valvas cardiacas, cirurgia.

\section{INTRODUÇÃO}

O tratamento cirúrgico das infecçōes do coração e grandes vasos teve início em 1940, quando TOUROFF \& VESSEL ${ }^{14}$ obtiveram cura da infecção de um canal arterial, por sua ligadura.

KAY et alii ${ }^{10}$, em 1961, publicaram o caso de 1 paciente com endocardite fúngica da tricúspide e comunicação interventricular, cuja erradicaçāo foi obtida pela retirada da vegetação e fechamento do defeito septal.

WALLACE et alii ${ }^{15}$, em 1965 , iniciaram nova era no tratamento das endocardites, ao realizarem excisão em valva aórtica infectada e sua substituição protética.

A partir de então, a substituição de valvas cardiacas infectadas passou a ser extensamente utilizada na prática cirúrgica ${ }^{9,11}$.
Seu emprego nas infecçōes da valva tricúspide, em pacientes muitas vezes toxicômanos, tem sido acompanhado de grave morbi-mortalidade e recurrência freqüente ${ }^{5,12}$.

Por estes motivos, a valvectomia, não acompanhada de prótese, foi proposta por ARBULU et alii ${ }^{1}$ e tem sido realizada sendo necessária, por vezes, prótese valvar em um segundo tempo ${ }^{13,16}$.

Recentemente, o tratamento conservador da endocardite tricúspide, com excisão do tecido infectado e plastia da valva, tem sido registrado como alternativa no manejo cirúrgico da endocardite bacteriana aguda ${ }^{2,4}$. 6. 8,17 .

Apresentamos 1 caso cuja cura cirúrgica foi obtida por ressecçāo de uma grande vegetaçāo tricúspide e do tecido valvar adjacente, e plastia anular.

Trabalho realizado no Departamento de Cirurgia da Universidade Federal do Paraná. Curitiba, PR, Brasil

Entregue para publicaçāo em 30 de outubro, 1988.

- Do Departamento de Cirurgia da Universidade Federal do Paraná.

* Do Hospital das Clinicas da Universidade Federal do Paraná.

*. Do Departamento de Clínica Médica da Universidade Federal do Paraná

Endereço para separatas: Iseu A. Costa. Rua Carmelo Rangel, 816. 80420 Curitiba, PR, Brasil. 
COSTA, I. A.; MULASKI, J. C.; LOPES, L. R. M.; CUNHA, C. P.; SOUZA, A. M. - Cirurgia conservadora de endocardite bacteriana aguda da valva tricúspide. Rev. Bras. Cir. Cardiovasc., 3(2): 125-129, 1988.

\section{RELATO DE CASO}

R. T. K., 28 anos, branca, foi admitida no Hospital de Clínicas da Universidade Federal do Paraná em 6.7.88 com história de aborto, seguido de curetagem uterina. Três dias após a curetagem, iniciaram-se febre, calafrios, tosse, dor torácica e diarréia. Negava cardiopatia e outros antecedentes de importância.

Na internação, mostrava quadro clínico e laboratorial de infecção e os exames físico e radiológico eram sugestivos de pneumonia estafilocócica bilateral com derrame pleural direito.

Foi tratada com gentamicina $(60 \mathrm{mg} / 8 / 8 \mathrm{~h}$, I. M.) e vancomicina ( $500 \mathrm{mg} / 6 / 6 \mathrm{~h}, \mathrm{I}$. V.), apresentando hemocultura positiva para $S$. aureus.

Nos dias subseqüentes, apareceu sopro sistólico $++1++++$ em foco tricúspide.

Com suspeita de endocardite bacteriana, foi realizado ecocardiograma 2D, que revelou vegetação na valva tricúspide. (Figura 1).

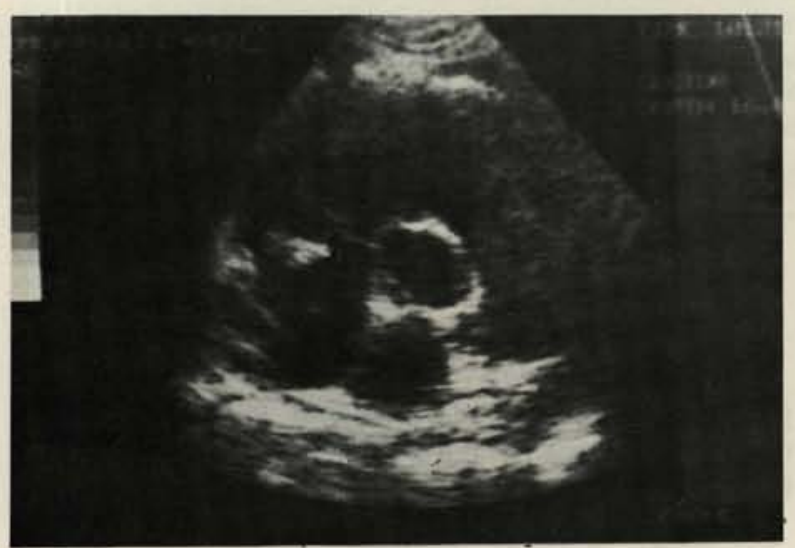

Fig. 1

Como houvesse piora das condições gerais e do quadro séptico, após 8 dias de uso de antibióticos e acentuação do sopro tricúspide, foi acrescentada oxacilina ( $1 \mathrm{~g} 6 / 6$ h, I. V.).

Vinte dias após a internação, persistindo o quadro infeccioso, apesar da melhora radiológica pulmonar, foi decidida intervenção cirúrgica.

A operação foi praticada em 25.7.88.

Praticou-se toracotomia mediana, com exposição do coração.

O pericárdio tinha aspecto normal, bem como o coração e grandes vasos. Não havia frêmito. Procedeu-se a canulação aórtica e das veias cavas, instalando-se circulação extracorpórea.
As veias cavas foram garroteadas em torno das cânulas, e o átrio direito, incisado, sem clampeio aórtico, ou injeção cardioplégica.

A valva tricúspide foi exposta, mostrando uma grande vegetação fungiforme, inserida na comissura entre as cúspides anterior e posterior, incluindo as bordas de ambas as cúspides. (Figura 2).

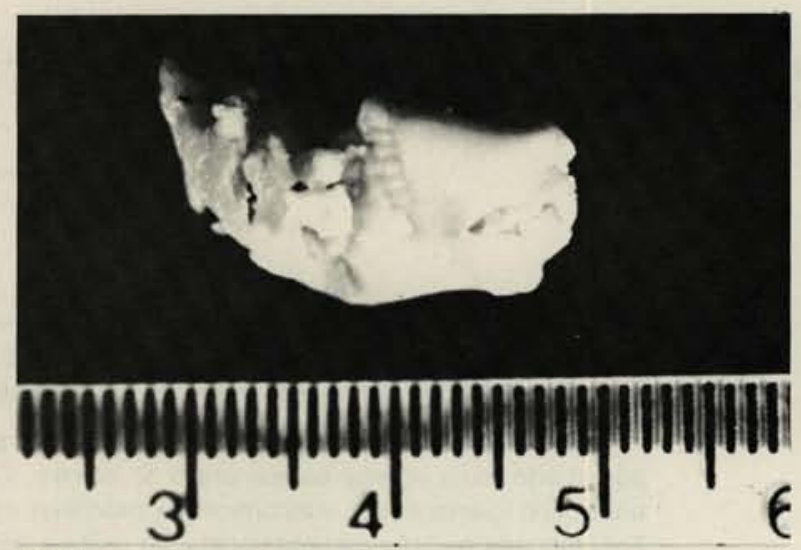

Fig. 2

A vegetação era friável e aderente ao tecido valvar, sendo removida por tração com pinça.

As bordas cuspidais foram excisadas na área de inserção da vegetaçẵo, nāo restando tecido lesado. Foram ressecadas algumas cordas inseridas no músculo papilar posterior.

A inspeção da cavidade ventricular direita não demonstrou presença de tecido infectado em seus tratos de entrada e saída.

A porção do anel tricúspide correspondente à cúspide posterior foi eliminada por plicatura com 2 pontos em $U$ de Ethibond 00 , sendo estes sepultados por chuleio contínuo de prolene $3 / 0$, apanhando a parede atrial adjacente (Figura 3).

O teste por injeção intraventricular de soro mostrou boa competência.

A atriotoma direita foi fechada e, com o aquecimento, houve estabilização das condições cardiovasculares.

A intervenção foi concluída sem intercorrências.

A evoluçāo pós-operatória foi favorável, passando a paciente a mostrar-se afebril, com melhora progressiva das condições gerais e do quadro radiológico pulmonar.

Medicação antibiótica, com oxacilina e gentamicina, foi mantida até o 30: dia após a intervenção.

A paciente teve alta em bom estado, afebril, com exame cardiovascular mostrando, apenas, sopro sistó- 
COSTA, I. A.; MULASKI, J. C.; LOPES, L. R. M.; CUNHA, C. P.; SOUZA, A. M. - Cirurgia conservadora de endocardite bacteriana aguda da valva tricúspide. Rev. Bras. Cir. Cardiovasc., 3(2): 125-129, 1988.

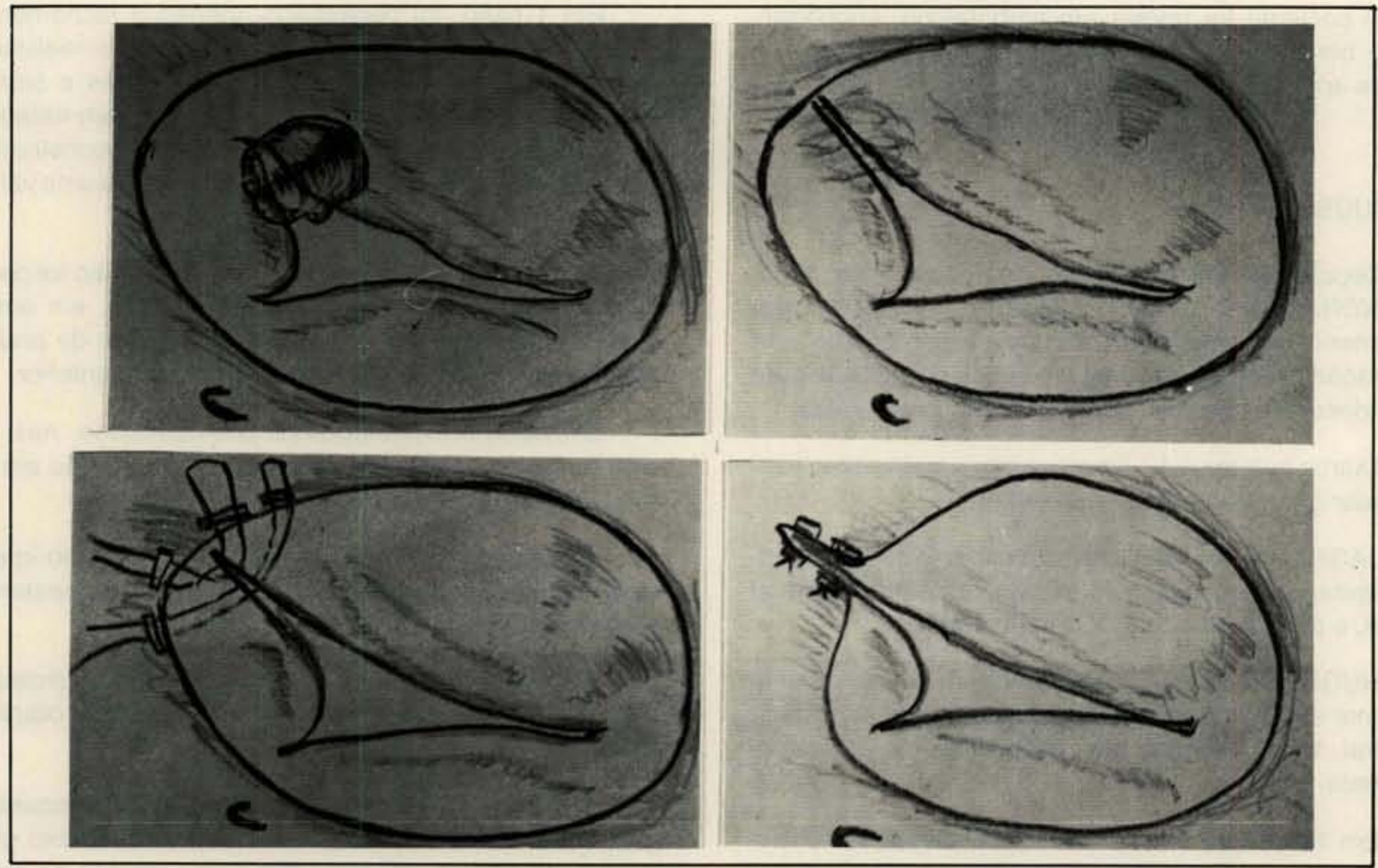

Fig. 3

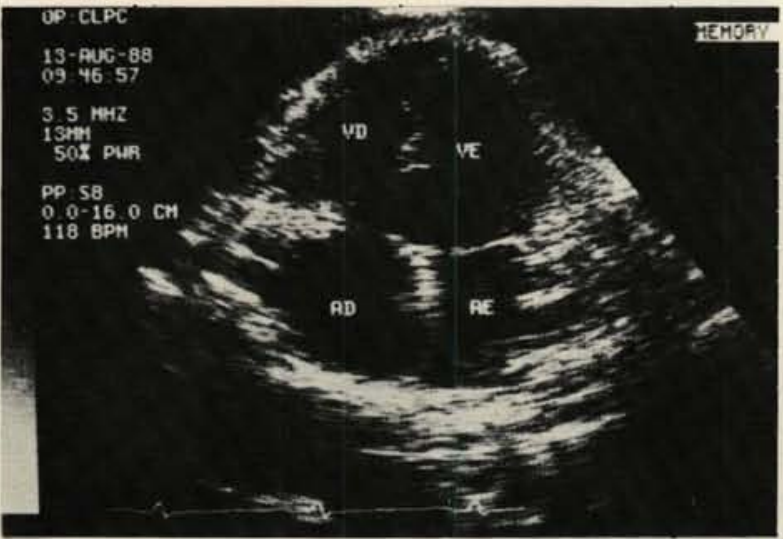

Fig. 4

lico $+l++++$ no foco tricúspide, sem sinais de insuficiência valvar.

O ecocardiograma 2D com Doppler, em 13.8.88, mostrou valva tricúspide espessada e imóvel em sua porção lateral, com folhetos móveis e delgados na porção septal (Figura 4).

Átrio e ventriculo direito de dimensões normais.

O Doppler-ecocardiograma mostrou valva tricúspide com gradiente de $4 \mathrm{mmHg}$ e área estimada em 2,44 $\mathrm{cm}^{2}$ e leve insuficiência tricúspide (Figura 5).

O exame anatomopatológico mostrou tecido conjuntivo com amplas áreas de deposição de fibrina, restos celulares, polimorfonucleares e colônias bacterianas.

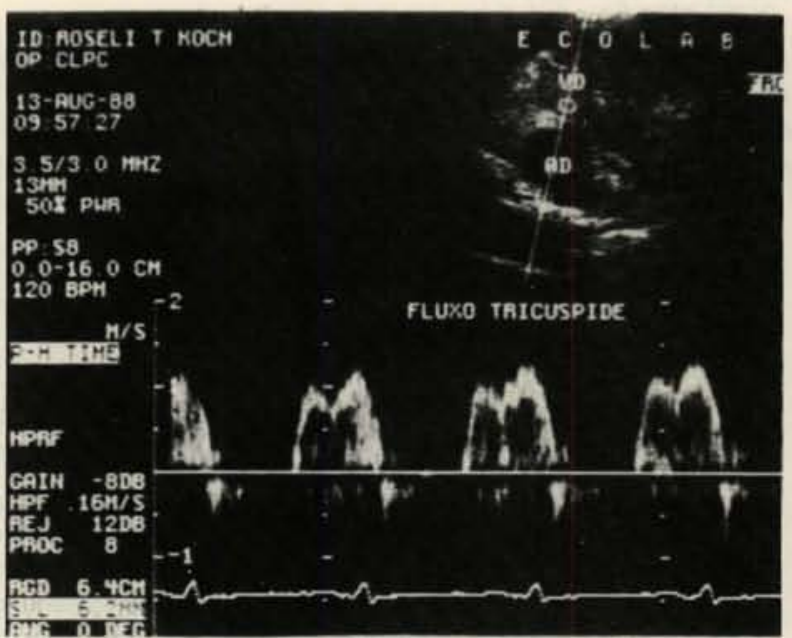

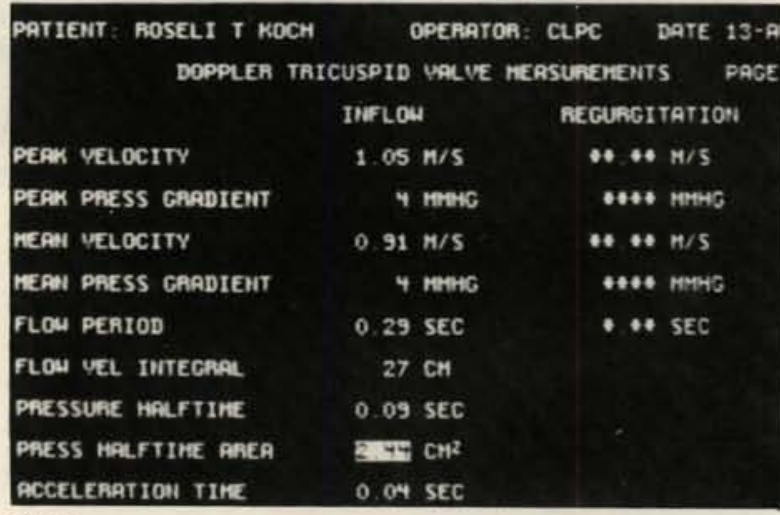

Fig. 5 
COSTA, I. A.; MULASKI, J. C.; LOPES, L R. M.; CUNHA, C. P.; SOUZA, A. M. - Cirurgia conservadora de endocardite bacteriana aguda da valva tricúspide. Rev. Bras. Cir. Cardiovaso., 3(2): 125-129, 1988.

A paciente foi revista em ambulatório, encontrando-se bem, com provas laboratoriais normalizadas, 3 meses após a intervenção.

\section{DISCUSSÃO}

Depois do relato pioneiro de KAY et alii ${ }^{10}$, em 1961 , CHANDRARATNA et alii ${ }^{2}$, publicaram, em 1970, aparentemente o primeiro caso em que a ressecçāo de uma vegetaçāo infectada da valva tricúspide possibilitou cura de endocardite primária, com conservação da valva.

Outros autores ${ }^{3,4,7}$ empregaram o tratamento conservador de valvas mitrais infectadas.

JAGGER et alii ${ }^{8}$ realizaram a excisāo de uma grande vegetação tricúspide com plicatura localizada do anel valvar, e cunharam o termo "vegetectomia".

HUGHES \& NOBLE ${ }^{6}$ apresentaram o caso de uma paciente em que 2 episódios de endocardite, tricúspide e mitral, foram tratados por ressecçção da vegetação infectada.

Em 1988, YEE \& ULLYOT ${ }^{17}$ publicaram sua experiência com os procedimentos reparadores na endocardite do coração direito.

Em 12 casos de acometimento tricúspide, foi possível realizar limpeza, sem sacrifício das cúspides ou das estruturas de sustentação, em 10 , sendo necessárias próteses nos 2 restantes.
Em 1 caso, foi necessário apenas o fechamento de um orifício na cúspide anterior; em 4, foi realizada excisão segmentar das cúspides posteriores e septal com valvoplastia limitada. Três pacientes foram tratados por excisão extensa em 2 cúspides, com reconstrução às custas de parches de pericardio, criando-se uma valva bicúspide.

Em 3 casos, a reconstrução com pericárdio foi complementada com uma anuloplastia limitada; em outro caso, foi necessária implantação de um anel de anuloplastia, após extensa ressecçāo da cúspide anterior.

O estudo ecocardiográfico pós-operatório, nos 11 sobreviventes, mostrou ausência de regurgitação em 5 , refluxo de + em 4 casos, e ++ em 2 casos.

Em nosso caso, após retirada da vegetação infectada, foram excisadas as bordas das cúspides posterior e anterior e de algumas cordas comissurais.

A competência valvar foi restabelecida por plicatura do anel, eliminando a porção correspondente à cúspide posterior.

A evolução pós-operatória, controlada ecocardiograficamente, demonstrou refluxo leve, com baixo gradiente transvalvar, não havendo sinais clínicos de estenose tricúspide.

O tratamento conservador da endocardite das valvas atrioventriculares deve estar na mente do cirurgião, como uma alternativa, em alguns casos de endocardite bacteriana aguda.

COSTA, I. A.; MULASKI, J. C.; LOPES, L. R. M.; CUNHA, C. P.; SOUZA, A. M. - Conservative operation for bacterial endocardites of the tricuspide valve. Rev. Bras. Cir. Cardiovasc., 3(2): 125-129, 1988.

ABSTRACT: One case of acute bacterial endocarditis of the tricuspid valve caused by $S$. aureus and following a septic abortion is presented. Surgical treatment was indicated after failure of antibiotics. Operation consisted of excision of a large vegetation adherent to the anterior and posterior cusps at the commisure and of the affected valvar tissue. Annular plicature at the segment corresponding to the posterior cuspid was employed to maintain competence. Clinical result was very satisfactory with resolution of sepsis. Dopplerecocardiography revealed the presence of the vegetation before the operation and showed a small regurgitation after valvoplasty. Conservative operation upon the atrioventricular valves must be kept in mind as an alternative in the treatment of acute bacterial endocarditis.

DESCRIPTORS: bacterial endocarditis, surgery; heart valves, surgery. 


\section{REFERÊNCIAS BIBLIOGRÁFICAS}

1 ARBULU, A.; THOMS, N. W.; CHISCANO, A.; WILSON, R. F. - Total tricuspid valvulectomy without replacement in the treatment of Pseudomonas endocarditis.

Surg. Forum, 22: 162-164, 1971.

2 CHANDRARATNA, P. A. N.; REAGAN, R. B.; IMAIZUMI, T.; LANGEVIN, E.; ELKINS, R. C. - Infective endocarditis cured by ressection of a tricuspid valve vegetation. Ann. Int. Med., 89 (4): 517-518, 1978.

3 FLEISHER, A. G.; DAVID, I.; MOGTADER, A.; HUTCHINSON, J. E. - Mitral valvuloplasty and repair for infective endocarditis. J. Thorac. Cardiovasc. Surg., 93 (2): 311-315, 1987.

4 Gammage, M. D.; LitTleR, W. A.; ABRAMS, L. D. Conservative surgery of the mitral valve in bacterial endocarditis. Thorax, 39 (11): 868-871, 1984.

5 GRAHAM, D. Y.; REAL, G. J.; MARTIN, R.; MORTON, J.; KENNEDY, J. H. - Infective endocarditis in drug addicts: experiences with medical and surgical treatment. Circulation, 48 (Supl. 3): 37-41, 1973.

6 HUGHES, C. F. \& NOBLE, N. - Vegetectomy: an alternative for infective endocarditis of the atrioventricular valves in drug addicts. J. Thorac. Cardiovasc. Surg., 95 (5): 857-861, 1988.

7 HARTYÁNSKY, I. L.; LOSÁDIK, K.; HÜTL, T. - Successful surgical management of mitral valve endocarditis in a 13-month-old child. J. Thorac. Cardiovasc. Surg., 96 (5): 831-832, 1988

8 JAGGER, S. D.; McCOUGHAN, B. C.; PWSEY, C. G. K. - Tricuspid valve endocarditis cured by excision of a single vegetation. Am. Heart J., 112 (3): 626-627, 1986.
9 JUNG Jr., Y.: SAAB, S. B.; ALMOND, C. . - The case for early surgical treatment of left-sided primary infective endocarditis: a collective review. J. Thorac. Cardiovasc. Surg., 70 (3): 509-518, 1975.

10 KAY, J. H.; BERNSTEIN, S.; FEINSTEIN, D.; BIDDLE, M. - Surgical cure of Candida abbicans endocarditis with open-heart surgery. $\quad$ N. Engl. J. Med., 264 (18): 907-910, 1961

11 MANHAS, D. R.; MOHRI, H.; HASSEL, E. A.; MERENDINO, K. A. - Experience with surgical management of primary infective endocarditis: a collected review of 130 patients. Am. Heart J., 84 (6): 738-747, 1972.

12 MILLS, S. A. - Surgical management of infective endocarditis. Ann. Surg., 195 (4): 367-383, 1982.

13 SIMBERKOFF, M. A.; ISOM, W.; SMITHIVAS, T. - Twostage tricuspid valve replacement for mixed bacterial endocarditis. Arch. Int. Med., 133 (2): 212-216, 1974.

14 TOUROFF, A. S. W. \& VESSEL, H. - Subacute Streptococcus viridans endarteritis complicating patent ductus arteriosus. JAMA, 115 (15): 1270, 1940.

15 WALLACE, A. G.; YOUNG, Jr., Y.; OSTERHOUT, S. Treatment of acute bacterial endocarditis by valve excision and replacement. Circulation, 31 (3): 450-453, 1965.

16 WRIGHT, J. S. \& GLENMIE, J. S. - Excision of tricuspid valve with later replacement in endocarditis of drug addiction. Thorax, 33 (4): 518-519, 1978.

17 YEE, E. S. \& ULLYOT, D. J. - Reparative approach for right-sided endocarditis: operative considerations and results of valvuloplasty. J. Thorac. Cardiovasc. Surg., 96 (1): 133-140, 1988. 